\title{
DEVELOPMENT OF EMPLOYEE TRAINING AND CO-OPERATIVE PLANNING
}

\author{
By J. A. D. McDONALD ${ }^{1}$
}

The general introduction and development of forest management practices is today a reality in British Columbia. As a result, the logging industry has had to tailor its production to fit the available growth. Any factor which reduces the productive capacity of the managed unit is a direct threat not only to the income of the men employed in the industry but to the economy of the entire community.

The threat of destruction from fire is one which will exist as long as we have trees and today, in dealing with this subject, I would like to offer several suggestions which many feel are prerequisite in effecting better fire prevention and pre-organization planning. I don't suggest that these proposals are the entire answer nor do I even suggest that they are entirely original; however, I do think that it is of paramount importance that we come to grips with the problem of co-operative planning by Government and Industrial agencies to their mutual benefit.

There are two major types of managed units in British Columbia: Tree Farm Licences and Public Working Circles. Their objectives are similar.

The Tree Farm Licence is approved and granted in the name of a single company which is responsible for the effective management and protection of the entire area within its boundaries. These licences are generally held by the larger companies and particularly on the Coast, where there may be from 100 to 300 men on the operation, they have already reached a high level of efficiency in their pre-organization for the control of fires.

The Public Working Circle is, on the other hand, managed and protected by the Forest Service. The only exception being the protection of areas on which licensees are actually in occupation, i.e. active timber sales. The annual allowable cut is sold by public auction and there may be as many as twenty-five different companies in occupation at any one time. Although each is responsible for the protection of its actual area of occupation, the area thus alienated never amounts to more than five percent of the total acreage of the Working Circle at any one time. The remaining 95 percent is entirely the legal responsibility of the Forest Service.

I say legal responsibility only to differentiate it from the moral responsibility of the licensees who are dependent on the growth from the entire unit. They have not only a moral responsibility to themselves, their workmen and their community, but they also have a tremendous financial stake in a Working Circle due to their large capital investment and the need for a continued supply of raw materials.

The licensees are generally aware of their responsibility in the matter of adequate protection and are, for the most part, willing to participate in cooperative planning if given direction.

\footnotetext{
${ }^{3}$ Forester i/c Protection, B.C. Forest Service, Prince George, B.C.
} 
Two suggestions are offered.

The first concerns the development of an employee training program as an aid to better pre-organization. The B.C. Forest Service has long preached the gospel in fire prevention but no organized effort has ever been made to actually teach the men working in the woods fire prevention nor has the need for pre-organization ever been explained. Every time I see a fire cause reported as carelessness. I wonder if it should read uninformed instead. Is a man careless because he doesn't know exactly why fires burn or because he doesn't know the meaning of inflammability or hazard and risk, or the meaning of moisture content, relative humidity, night recovery or hazard build up? I doubt it! However, if an employee is instructed in an interesting and informative way, the meaning of all these terms becomes clear. They can then be related to the cause of fires and the precaution he must take to prevent their starting or spreading. Then, once aware of his responsibilities, he will generally co-operate willingly.

It goes without saying that trained men will greatly increase the effectiveness of any pre-organization plan. Not only will they have some idea what they are required to do in a fire emergency, they will also know why!

The second suggestion relates to the need for co-operative planning by all licensees to take voluntary initial action on any fire within the limits of their Working Circle. The more intensive management practices should beget more intensive protection; however, with the realization that additional staff and funds are generally not forthcoming in any large amounts, we must make every effort to improve protection standards with existing facilities. What we in this region propose is this-each lumber operator, depending on the size of his operation, should designate two or three trained and equipped men to take initial action on any fire immediately it is seen or reported.

This system would offer a two-fold advantage over the present policy whereby the Ranger and his staff must organize and despatch the initial crew from his district headquarters. First it will result in a faster initial attack as these crews are already in the vicinity. Secondly, trained men will be the first to reach the fire while it is still small to take more effctive suppression measures. In addition, in the event of the fire blowing up on them, this nucleus of trained men will assist greatly in the smooth and efficient expansion of the crew to a major attack force.

Further to the co-operative measures we would also suggest that protection committees be formed which include members from all Working Circles or other managed units. This would allow a free exchange of opinions on problems confronting the district as a whole.

This problem of mutual understanding and co-operation for the integration of Government and Industrial agencies has been resolved to a degree in this region and we have in fact $t w o^{2}$ Working Circles actively participating under the suggested scheme. The only deterrent to its general application is the lack of sufficient staff, on the part of the B.C. Forest Service, to organize the necessary program.

\footnotetext{
"Since this report was delivered four more Working Circle Associations have undertaken co-operative planning measures.
} 